\title{
Sodium Alginate-Zinc Oxide Nanocomposite Film for Antibacterial Wound Healing Applications
}

\author{
Siti Natrah Abdul Bakil ${ }^{1}$, Hazirah Kamal ${ }^{1}$, Hasan Zuhudi Abdullah ${ }^{1}$, Maizlinda Izwana Idris ${ }^{1, *}$ \\ 1 Department of Manufacturing Engineering, Faculty of Mechanical and Manufacturing Engineering, Universiti Tun \\ Hussein Onn Malaysia, 86400 Parit Raja, Batu Pahat, Johor, Malaysia \\ * Correspondence: izwana@uthm.edu.my;
}

Scopus Author ID 57202025539

Received: 23.04.2020; Revised: 4.05.2020; Accepted: 7.05.2020; Published: 12.05.2020

\begin{abstract}
This study aims to develop sodium alginate (SA) based $\mathrm{ZnO}$ nanoparticles as antibacterial film for wound healing applications. As natural materials, sodium alginate has been widely investigated and used in wound healing. The $\mathrm{ZnO}$ nanoparticles were incorporated as antibacterial into sodium alginate with different compositions $(2,4,6,8,10 \mathrm{ml})$. Solvent casting method was performed to prepare a film. The film was characterized by using Fourier Transform Infrared Spectroscopy (FT-IR), Atomic Force Microscopy (AFM) and Field Emission Scanning Electron Microscopy (FESEM). Effectiveness of antibacterial activity was carried out against Gram-negative (Escherichia coli) and Gram-positive (Staphylococcus aureus) to characterize the sample. The results from microstructure analysis indicated that as $\mathrm{ZnO}$ nanoparticle compositions increased, the film surface became rough. It was found that sodium alginate incorporated with $\mathrm{ZnO}$ had slightly higher antibacterial activities against S. aureus than E. coli. Thus, sodium alginate $(\mathrm{SA})$-Zinc oxide $(\mathrm{ZnO})$ nanoparticle has the potential to be used as a wound healing material in biomedical applications.
\end{abstract}

Keywords: Wound healing; Sodium Alginate; ZnO.

(C) 2020 by the authors. This article is an open access article distributed under the terms and conditions of the Creative Commons Attribution (CC BY) license (https://creativecommons.org/licenses/by/4.0/).

\section{Introduction}

The skin is an important organ of the body; it protects the internal organs and it is responsible for the protection against pathogens and dehydration from environment aggressions by acting as a physical/chemical barrier [1-3]. Any damage to the skin results in wounds. Wounds can be with or without tissue loss and acute or chronic. It repairs and remodels the skin after damage. It consists of four overlapping steps, biochemical, and cellular processes. These processes include overlapping steps like hemostasis (cell migration), inflammation (formation of new blood vessels), proliferation and remodeling (regeneration of skin barrier and connective tissues). These steps involve many cells and growth factors. Wounds are naturally cured by the wound healing process [4-5].

Nowadays, biopolymers represent an important class of materials widely used for several purposes, such as biomedical [7], pharmaceutical and environmental applications [8]. Among these materials, alginate has attracted a lot of interests due to its biocompatibility, biodegradability, biological activity, low cost, water-solubility, and ease of production and functionalization [9]. Alginates are particularly interesting due to their high exudate absorbency and constitute a major segment in the synthetic wound care market. Sodium alginate is a natural polysaccharide, it is chemically the sodium salt of alginic acid, an unbranched copolymer with homopolymeric blocks of $\beta$-1,4-linked-d mannuronic acid and $\alpha$ - 
1,4-linked-l-guloronic acid. It can be easily cross-linked using divalent cations such as $\mathrm{Ca}^{2+}$, $\mathrm{Sr}^{2+} \mathrm{Zn}^{2+}$ and others [7]. The fluid absorption and swelling behavior of the alginate are controlled by the divalent cation concentration in the biopolymer solution [10].

Bio nanocomposites are a combination of biopolymers and in organic materials, mainly from metal oxide like silver nitrate, titanium oxide $\left(\mathrm{TiO}_{2}\right)$, silicon oxide $\left(\mathrm{SiO}_{2}\right)$, and zinc oxide $(\mathrm{ZnO})$ in nano dimension size. Superior mechanical strength, high thermal resistance and low permeability are the properties of biocomposite. In recent years, bio nanocomposites have been used as wound dressings as well [5,11-12]. Among nanoparticles used in wound dressings is zinc oxide $(\mathrm{ZnO})$. The outstanding properties of $\mathrm{ZnO}$ are antibacterial, inexpensive and nontoxic, which do not show any harmful effects to normal body cells. Usually, these cells consist of keratinocytes which release $\mathrm{Zn}$ ions when a wound occurs on the surface of the skin. This specific mechanism accelerates the wound healing process with time [13-14]. It has been reported that $\mathrm{ZnO}$ enables the inhibition of the adhesion and internalization of E. coli bacteria. Thus, wound healing can be promoted by using well-designed film which is able to regulate fibroblast migration and activates macrophages and bacterial death. In addition, $\mathrm{ZnO}$ nanoparticles are known for reducing the attachment and viability of microbes on biomedical surfaces [15-16]. One of the most important things is the particle size of $\mathrm{ZnO}$ which controls antibacterial activities [17].

Owing to the high relevance of sodium alginate in wound healing applications, it has been chosen to incorporate with $\mathrm{ZnO}$. Therefore, the main objective of the present study is to develop sodium alginate films incorporated with $\mathrm{ZnO}$ nanoparticles in order to characterize the film properties and access antibacterial activities.

\section{Materials and Methods}

\subsection{Preparation of the Sodium Alginate/Zinc Oxide Film.}

Sodium alginate and $\mathrm{ZnO}$ nanoparticles were purchased from Sigma Aldrich. Sodium alginate with a concentration of $1 \mathrm{wt} \%$ was prepared by dissolving 1.0 gram of sodium alginate into $100 \mathrm{ml}$ of distilled water. Subsequently, the solution was stirred at $100 \mathrm{rpm}$ at room temperature until completely dissolved. After that, different $\mathrm{ZnO}$ nanoparticles $(2,4,6,8,10$ $\mathrm{ml}$ ) as shown in Table 1, were added and further stirred for 30 minutes. In order to produce film, $10 \mathrm{ml}$ of solution was dried for one hour. Next, the dried solution was cross-linked with $10 \mathrm{ml}$ of $\mathrm{CaCl}_{2}$ solution and the film was formed after 24 hours drying process.

Table 1. Composition of sodium alginate with $\mathrm{ZnO}$.

\begin{tabular}{l|l|l}
\hline Sodium Alginate $(\mathbf{m l})$ & ZnO $(\mathbf{m l})$ & Designation Sample \\
\hline 100 & - & SA \\
\hline 98 & 2 & SZ2 \\
\hline 96 & 4 & SZ4 \\
\hline 94 & 6 & SZ6 \\
\hline 92 & 8 & SZ8 \\
\hline 90 & 10 & SZ10 \\
\hline
\end{tabular}

\subsection{Physico-chemical characterization.}

Fourier Transform Infrared Spectra (FTIR) of sodium alginate, sodium alginate/zinc oxide films were characterized using Spectrometer Perkin Elmer (Spectrum 100-FTIR, USA) in the range of $400-4000 \mathrm{~cm}^{-1}$. The surface roughness of the sample was measured using Atomic Force Microscopy (AFM, Park System XE-100, Korea) within $1 \mathrm{~cm}$ x $1 \mathrm{~cm}$ area. The 
surface morphology of the film was observed by Field Emission Scanning Electron Microscopy (FESEM, JEOL- 7600F, Japan). All samples were examined using an accelerating voltage of $10 \mathrm{kV}$. Antimicrobial activities of the films were prepared using Kirby-Bauer disc diffusion method. Briefly, inocula bacteria of E. coli and S. aureus were prepared from fresh colonies of Mueller Hinton. These pathogenic bacteria were selected due to their serious life-threatening effects. Circular films with $10 \mathrm{~cm}$ diameter were prepared and placed on the colonized agar plates and incubated for 24 hours (at a temperature of $37^{\circ} \mathrm{C}$ ) and then zone inhibition in millimeters was subsequently determined using a digital Vernier Caliper.

\section{Results and Discussion}

\subsection{Fourier Transform IR Spectroscopy (FT-IR).}

FTIR analysis was performed to examine the interaction between sodium alginate and $\mathrm{ZnO}$. The spectra profile of pure sodium alginate (SA) and different compositions (SAZ2, SAZ4, SAZ6, SAZ8 and SAZ10) are shown in Figure 1. Some absorption peaks appeared at $3253,1549,1411$ and $1025 \mathrm{~cm}^{-1}$.

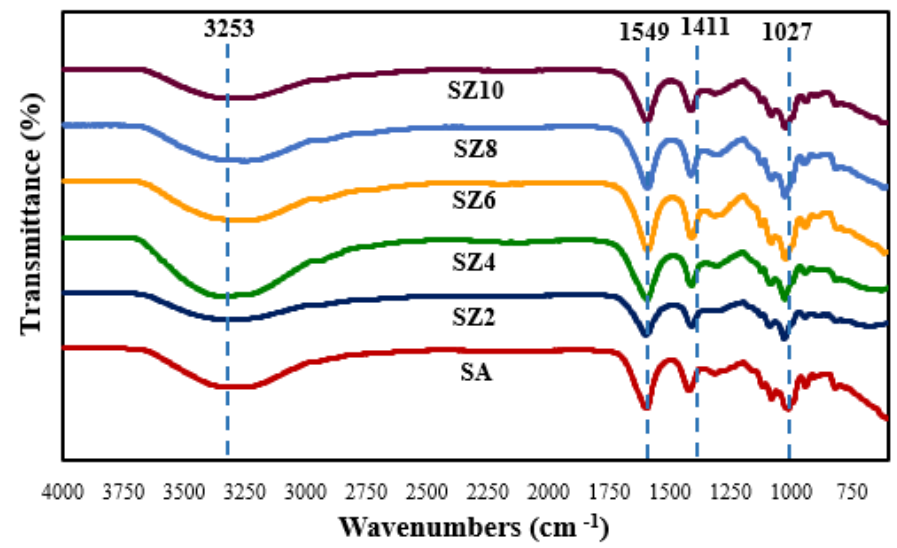

Figure 1. FT-IR spectra of SA, SZ2, SZ4, SZ6, SZ8 and SZ10.

The characteristic of broad absorption band ranged in $3253-3240 \mathrm{~cm}^{-1}$, which was attributed to the stretching vibration to physically absorbed water. This is similar to those reported by A. Dodero [8]. The bands at $1549 \mathrm{~cm}^{-1}$ and $1411 \mathrm{~cm}^{-1}$ of SA, SZ2, SZ4, SAZ6, $\mathrm{SZ} 8$ and $\mathrm{SZ} 10 \mathrm{~cm}^{-1}$ are attributed to the stretching vibrations of the COO- groups. Nevertheless, the spectra at $1027 \mathrm{~cm}^{-1}$ correspond to $\mathrm{C}-\mathrm{O}-\mathrm{C}$ vibrations. By comparison, it seems that there is no significant difference between SA and SZ2, SZ4, SZ6, SZ8 and SZ10. This is similarly reported by Wang et al. [18] and S. Bakil et al. [19].

\subsection{Atomic Force Microscopy (AFM).}

Atomic force microscopy (AFM) was used to obtain information about the surface roughness of the sample. The image shown in Figure 2(a) is SA in comparison with SZ2, SZ4, SZ6, SZ8 and SZ10 (Figure 2(b-f). The combination of alginate and ZnO altered the topographic texture of the resulting films specifically, which revealed the surface's clear peaks and valley interlacements as shown in Figure 2(b-f). However, SA surface showed the smoothedge projection only. Therefore, the average roughness, $\mathrm{Ra}$, was taken for comparison in all samples as presented in Figure 3. It can be seen that SA showed the lowest Ra values (4.82 $\mathrm{nm})$ compared to other samples. Meanwhile, the highest value was SZ10 $(12.73 \mathrm{~nm})$. The 
results showed that the increasing $\mathrm{Ra}$ value by the addition of $\mathrm{ZnO}$ increased the roughness of the resulting film. It similar report by M.I Idris et al [20].
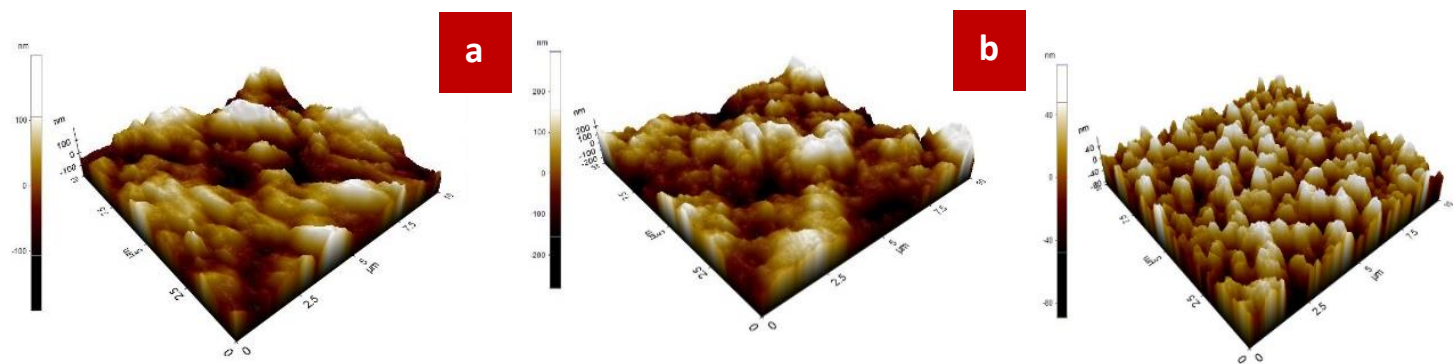

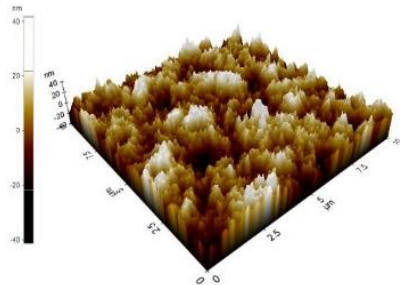

d

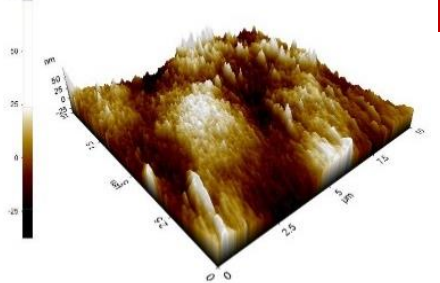

e

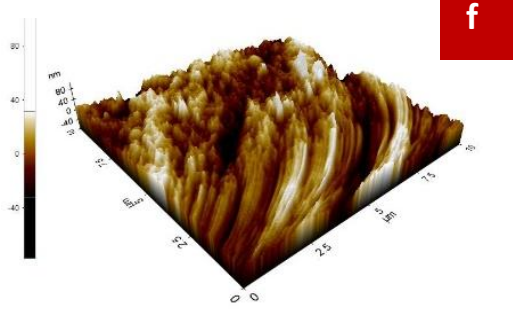

Figure 2. FT-IR spectra of (a) SA; (b) SZ2; (c) SZ4; (d) SZ6; (e) SZ8; and (f) SZ10.

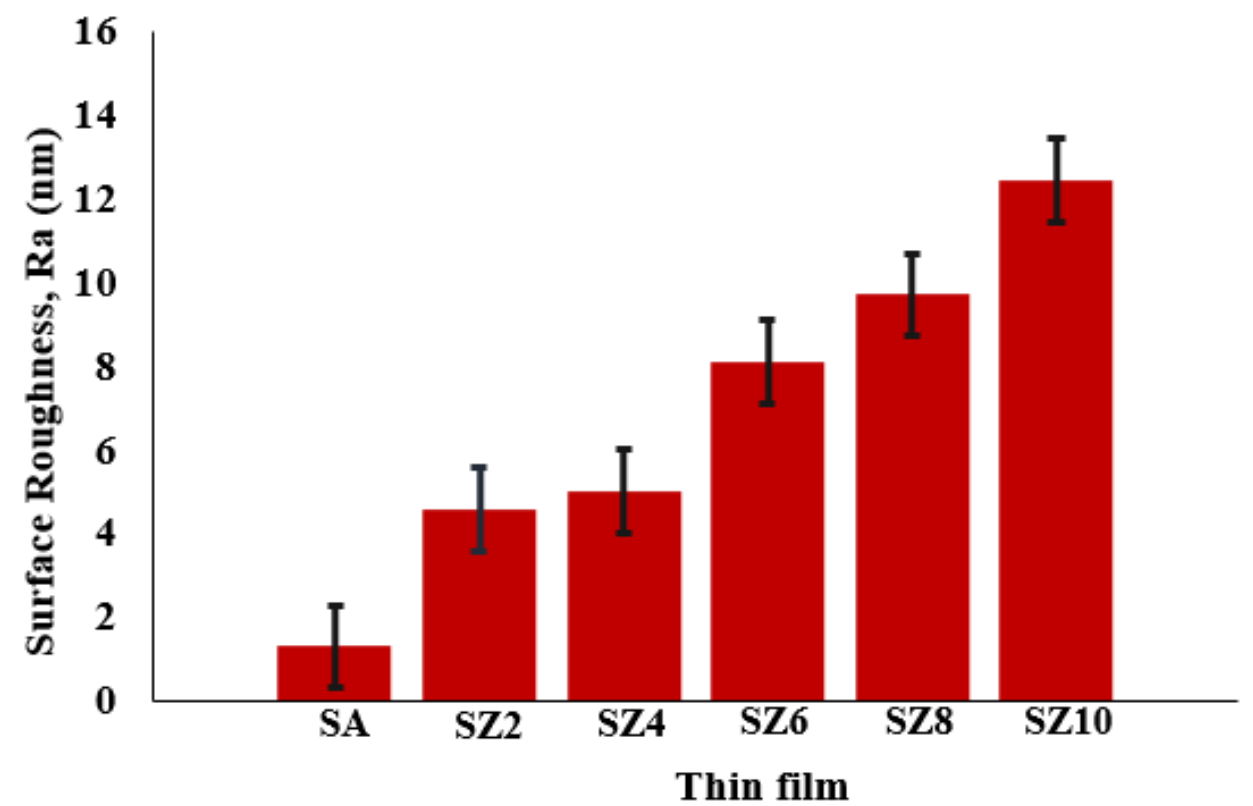

Figure 3. Surface Roughness, Ra values of various formulation AFM.

\subsection{Morphological Characterization.}

Figure 4(a-f) shows the FESEM images of SA, SZ2, SZ4, SZ6, SZ8 and SZ10 at 50,000 magnifications. The sodium alginate in Figure 4(a) shows the homogenous structure. Meanwhile, the addition of $\mathrm{ZnO}$ showed some agglomerations of particles in the sodium alginate matrix in Figure 4(b-f)). In addition, the $\mathrm{ZnO}$ particles were found to be in irregular shapes with different sizes. FESEM analysis showed that microstructure of SZ10 in Figure 4(f) had more agglomeration than other films. SEM-EDS was carried out to confirm the element of aggregation. The data revealed the peak corresponding to element $\mathrm{ZnO}$ as shown in Figure 5. This proved the distribution of $\mathrm{ZnO}$ over the sodium alginate matrix. 

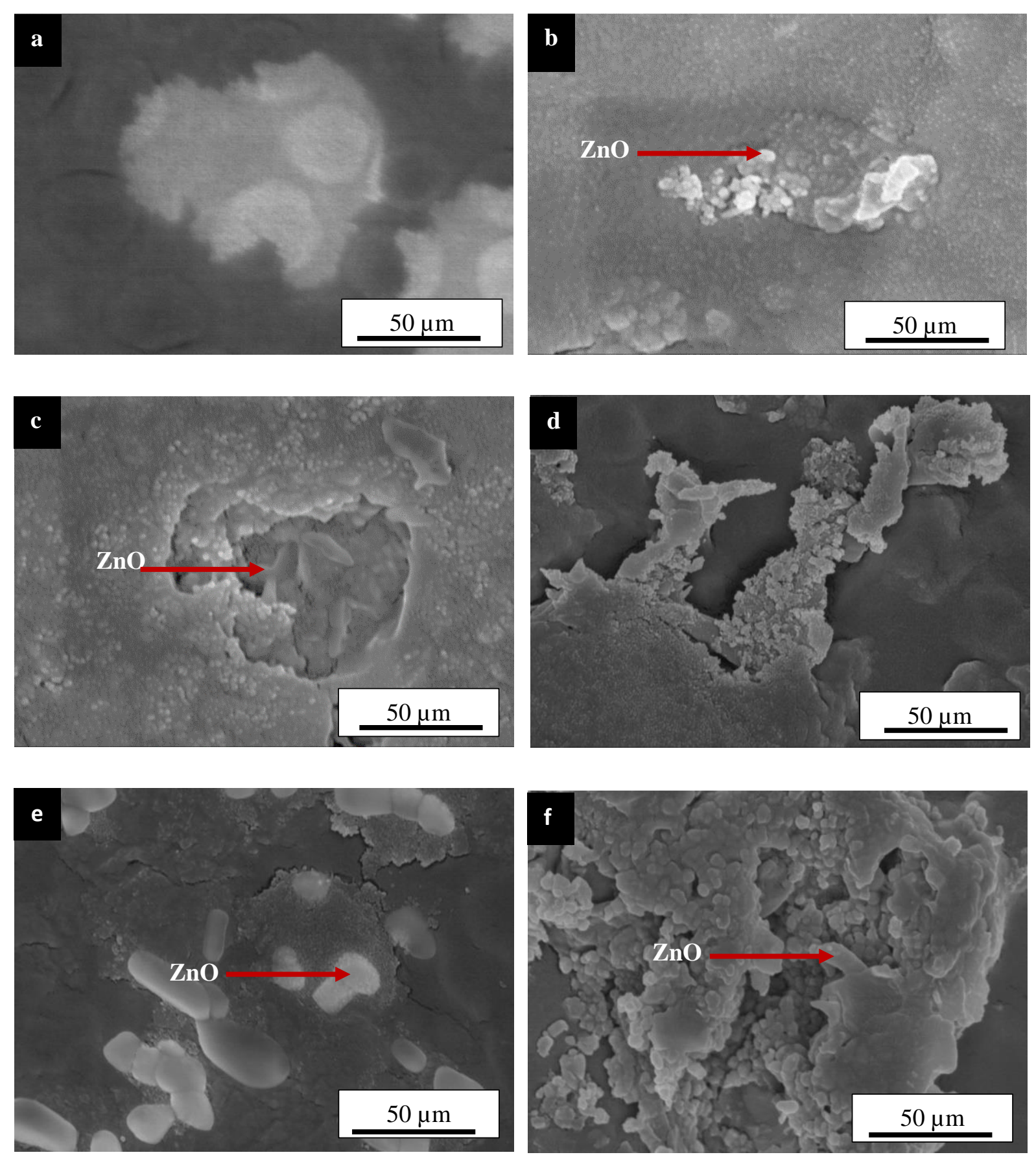

Figure 4. FESEM image of (a) SA; (b) SZ2 (c) SA4; (d) SZ6; (e) SZ8; (f) SZ10.

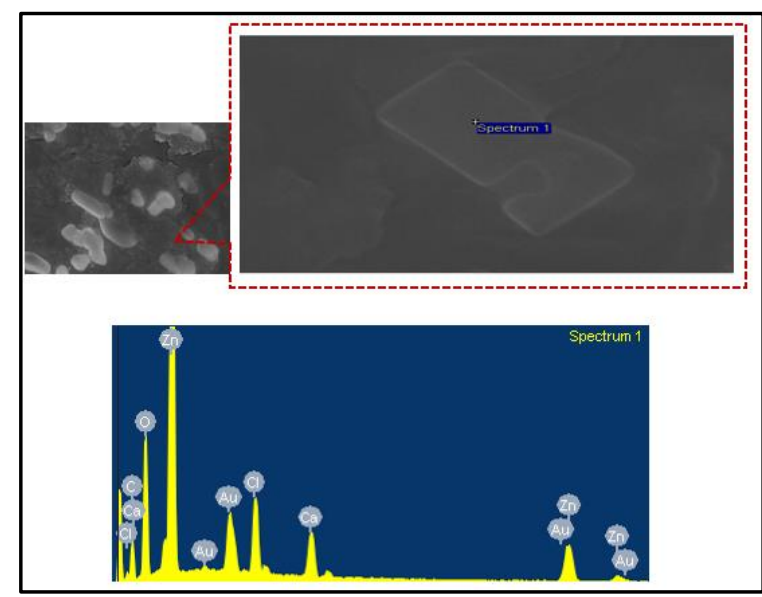

Figure 5. EDS Analysis of sample SZ8. 


\subsection{Antibacterial Activities.}

Antibacterial activities of all films were assessed by using Kirby-Bauer disc diffusion method. Destruction of bacteria was the key parameter that determined the antibacterial properties of sodium alginate $\mathrm{ZnO}$ film. The films were screened for their antibacterial activities against Gram-negative (E. coli) and Gram-positive (S. aureus) where the bacterial colony distributions are as shown in Figure 6 and Figure 7 respectively. Figure 6 shows the film containing $\mathrm{ZnO}$ with less significant antibacterial properties towards E. coli during 24 hours of incubations at $37^{\circ} \mathrm{C}$. On the other hand, SZ2 and SZ10 as shown in Figure 7 exhibited excellent antibacterial activities. As $\mathrm{ZnO}$ nanoparticles increased, the diameter of the inhibition zone also increased, and the highest inhibition zone was observed in SZ10 samples. This indicated that the diameter of the inhibition zone was independent of the $\mathrm{ZnO}$ compositions. Results showed that film containing $\mathrm{ZnO}$ was slightly more effective against Gram-positive (S. aureus) than Gram-negative (E. coli). Therefore, sodium alginate incorporated with $\mathrm{ZnO}$ showed strong potential as wound healing applications.

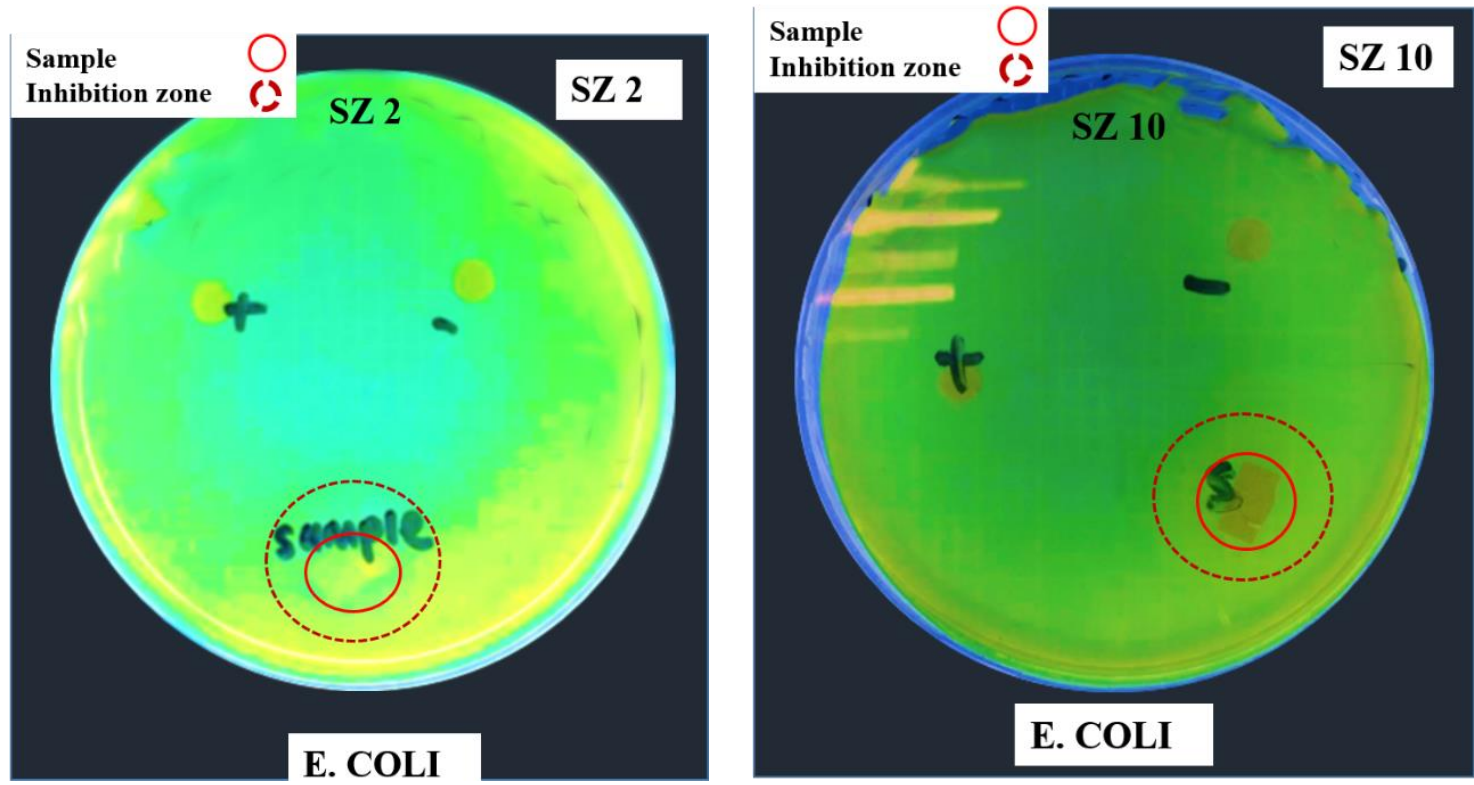

Figure 6. Antibacterial activity test of (a) SZ2 and (b) SZ10 againts E. coli.
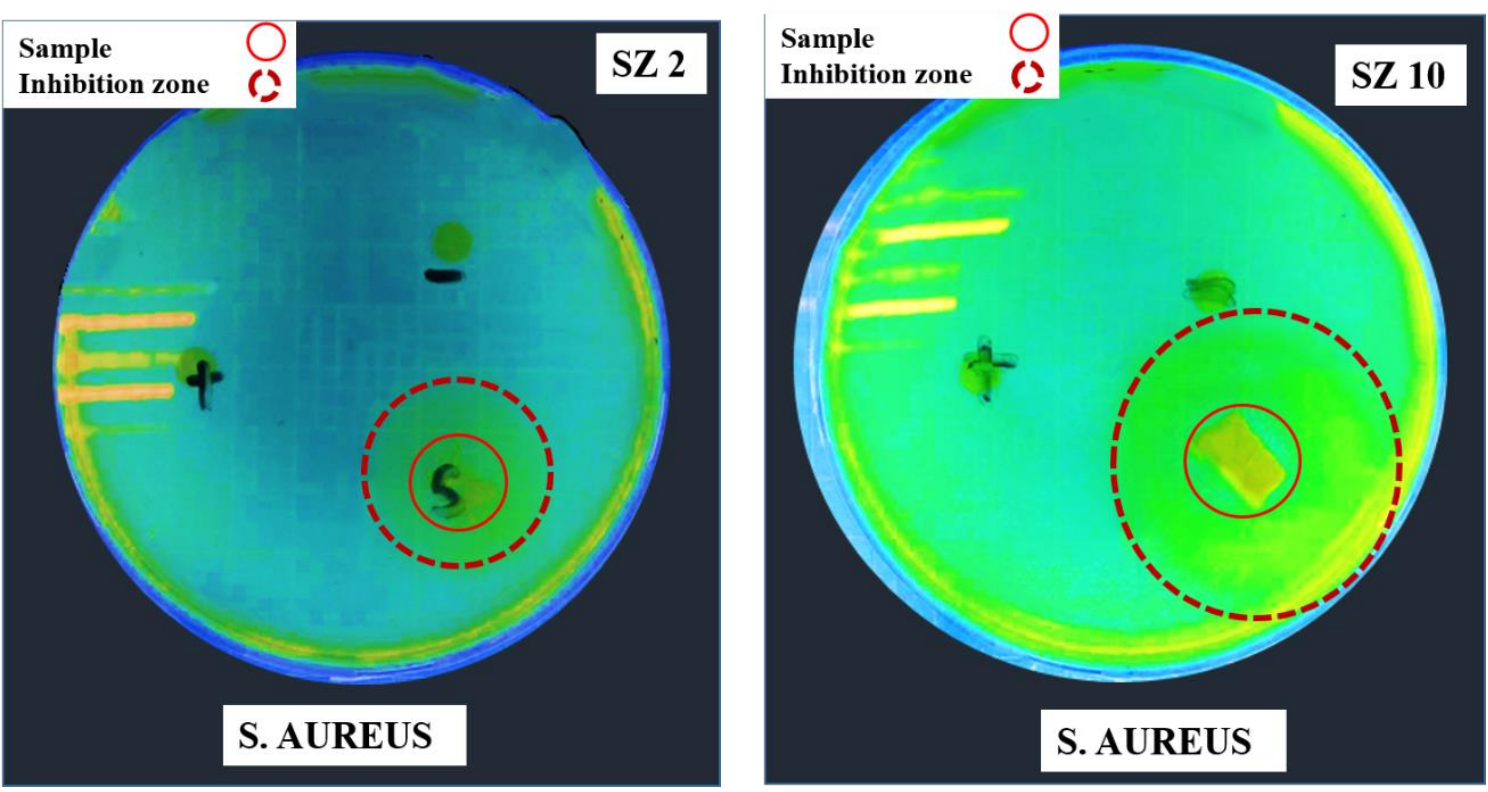

Figure 7. Antibacterial activity test of SZ2 and SZ10 againts S.aureus. 


\section{Conclusions}

The $\mathrm{ZnO}$ nanoparticle is incorporated into sodium alginate to develop antibacterial nanocomposite film toward wound healing applications. The solution casting method is used to prepare film and the resulting film is characterized using FT-IR, AFM, FESEM and antibacterial assessment. The surface morphology of biocomposite films noticeably consists of $\mathrm{ZnO}$ nanoparticles which are eventually distributed into sodium alginate matrix. Then, the surface roughness increases as the $\mathrm{ZnO}$ nanoparticles increase. The incorporation of $\mathrm{ZnO}$ nanoparticles into sodium alginate possesses antibacterial effect which inhibits the growth of various Gram-positive pathogens especially $\mathrm{S}$. aureus. It can be concluded that sodium alginate based $\mathrm{ZnO}$ nanocomposite films have the potential to be used in wound healing application. It can be used as a promising alternative to synthetic or petroleum based wound healing application.

\section{Funding}

This research received no external funding.

\section{Acknowledgments}

This research was supported by Fundamental Research Grant Scheme (FRGS/ K063) and Universiti Tun Hussein Onn Malaysia TIER 1 (H188).

\section{Conflicts of Interest}

The authors declare no conflict of interest.

\section{References}

1. Varaprasad, K.; Jayaramudu, T.; Kanikireddy, V.; Toro, C.; Sadiku, E.R. Alginate-based composite materials for wound dressing application:A mini review. Carbohydrate Polymers 2020, 236, https://doi.org/10.1016/j.carbpol.2020.116025.

2. Saghazadeh, S.; Rinoldi, C.; Schot, M.; Kashaf, S.S.; Sharifi, F.; Jalilian, E.; Nuutila, K.; Giatsidis, G.; Mostafalu, P.; Derakhshandeh, H.; Yue, K.; Swieszkowski, W.; Memic, A.; Tamayol, A.; Khademhosseini, A. Drug delivery systems and materials for wound healing applications. Advanced Drug Delivery Reviews 2018, 127, 138-166, https://doi.org/10.1016/j.addr.2018.04.008.

3. Amanzadi, B., Mirzaei, E., Hassanzadeh, G., Mahdaviani, P., Boroumand, S., Abdollahi, M. Majidi, R. F. Chitosan-based layered nanofibers loaded with herbal extract as wound-dressing materials on wound model studies. Biointerface Research in Applied Chemistry 2019, 9(4), 3979-3986. https://doi.org/10.33263/BRIAC94.979986.

4. Kaushik, M.; Niranjan, R.; Thangam, R.; Madhan, B.; Pandiyarasan, V.; Ramachandran, C.; Oh, D.-H.; Venkatasubbu, G.D. Investigations on the antimicrobial activity and wound healing potential of $\mathrm{ZnO}$

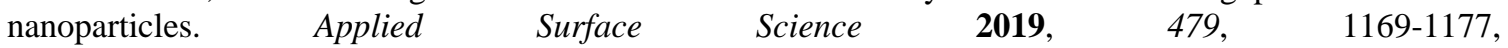
https://doi.org/10.1016/j.apsusc.2019.02.189.

5. Choi, J.; Park, Y.G.; Yun, M.S.; Seol, J.W. Effect of herbal mixture composed of Alchemilla vulgaris and Mimosa on wound healing process. Biomedicine \& Pharmacotherapy 2018, 106, 326-332, https://doi.org/10.1016/j.biopha.2018.06.141.

6. Abbasi, A.R.; Sohail, M.; Minhas, M.U.; Khaliq, T.; Kousar, M.; Khan, S.; Hussain, Z.; Munir, A. Bioinspired sodium alginate based thermosensitive hydrogel membranes for accelerated wound healing. International Journal of Biological Macromolecules 2020, 155, 751-765, https://doi.org/10.1016/j.ijbiomac.2020.03.248.

7. Rasool, A.; Ata, S.; Islam, A. Stimuli responsive biopolymer (chitosan) based blend hydrogels for wound healing application. Carbohydrate Polymers 2019, 203, 423-429, https://doi.org/10.1016/j.carbpol.2018.09.083.

8. Kanmani, P.; Rhim, J.-W. Properties and characterization of bionanocomposite films prepared with various biopolymers and $\mathrm{ZnO}$ nanoparticles. Carbohydrate Polymers 2014, 106, 190-199, http://dx.doi.org/10.1016/j.carbpol.2014.02.007. 
9. Dodero, A.; Alloisio, M.; Vicini, S.; Castellano, M. Preparation of composite alginate-based electrospun membranes loaded with ZnO nanoparticles. Carbohydrate Polymers 2020, 227, https://doi.org/10.1016/j.carbpol.2019.115371.

10. Raman, S.P.; Keil, C.; Dieringer, P.; Hübner, C.; Bueno, A.; Gurikov, P.; Nissen, J.; Holtkamp, M.; Karst, U.; Haase, H.; Smirnova, I. Alginate aerogels carrying calcium, zinc and silver cations for wound care: Fabrication and metal detection. The Journal of Supercritical Fluids 2019, 153, https://doi.org/10.1016/j.supflu.2019.104545.

11. Mehrabani, M.G.; Karimian, R.; Rakhshaei, R.; Pakdel, F.; Eslami, H.; Fakhrzadeh, V.; Rahimi, M.; Salehi, R.; Kafil, H.S. Chitin/silk fibroin/TiO2 bio-nanocomposite as a biocompatible wound dressing bandage with strong antimicrobial activity. International Journal of Biological Macromolecules 2018, 116, 966-976, https://doi.org/10.1016/j.ijbiomac.2018.05.102.

12. Zhou, L.; Yu, K.; Lu, F.; Lan, G.; Dai, F.; Shang, S.; Hu, E. Minimizing antibiotic dosage through in situ formation of gold nanoparticles across antibacterial wound dressings: A facile approach using silk fabric as the base substrate. Journal of Cleaner Production 2020, 243, https://doi.org/10.1016/j.jclepro.2019.118604.

13. Khorasani, M.T.; Joorabloo, A.; Moghaddam, A.; Shamsi, H.; MansooriMoghadam, Z. Incorporation of ZnO nanoparticles into heparinised polyvinyl alcohol/chitosan hydrogels for wound dressing application. International Journal of Biological Macromolecules 2018, 114, 1203-1215, https://doi.org/10.1016/j.ijbiomac.2018.04.010.

14. Subhasree, R. S., Selvakumar, D., \& Kumar, N. S. Hydrothermal Mediated Synthesis of ZnO Nanorods and Their Antibacterial Properties. Letters in Applied NanoBioScience 2012, 1(1), 2-7.

15. Balaure, P.C.; Holban, A.M.; Grumezescu, A.M.; Mogoşanu, G.D.; Bălşeanu, T.A.; Stan, M.S.; Dinischiotu, A.; Volceanov, A.; Mogoantă, L. In vitro and in vivo studies of novel fabricated bioactive dressings based on collagen and zinc oxide 3D scaffolds. International Journal of Pharmaceutics 2019, 557, 199-207, https://doi.org/10.1016/j.ijpharm.2018.12.063.

16. Medina-Ramírez, I.E.; Díaz de León-Macias, C.E.; Pedroza-Herrera, G.; Gonzáles-Segovia, R.; Zapien, J.A.; Rodríguez-López, J.L. Evaluation of the biocompatibility and growth inhibition of bacterial biofilms by $\mathrm{ZnO}, \mathrm{Fe} 3 \mathrm{O} 4$ and $\mathrm{ZnO} @ \mathrm{Fe} 3 \mathrm{O} 4$ photocatalytic magnetic materials. Ceramics International 2020, 46, 89798994, https://doi.org/10.1016/j.ceramint.2019.12.145.

17. Dwivedi, L.M.; Baranwal, K.; Gupta, S.; Mishra, M.; Sundaram, S.; Singh, V. Antibacterial nanostructures derived from oxidized sodium alginate-ZnO. International Journal of Biological Macromolecules 2020, 149, 1323-1330, https://doi.org/10.1016/j.ijbiomac.2020.02.011.

18. Wang, T.; Wang, J.; Wang, R.; Yuan, P.; Fan, Z.; Yang, S. Preparation and properties of ZnO/sodium alginate bi-layered hydrogel films as novel wound dressings. New Journal of Chemistry 2019, 43, 86848693, https://doi.org/10.1039/C9NJ00402E.

19. Bakil, S.N.A.; Abdullah, H.Z.; Selimin, M.A., Lee, T.C.; Idris, M.I. Bio-Composite of Sodium AlginateTitanium Dioxide for Wound Healing Applications. Scientific. Net. In Press.

20. Idris,M.I.; Azhari, M.F.; Bakil, S.N.A.; Selimin, M.A.; Lee, T.C,; Abdullah, H.Z. Surface Properties of Alginate/Chitosan Biofilm for Wound Healing Application. Scientific. Net. In Press. 